\title{
Performance Investigation of Heat Pipe Heat Exchanger as Energy Conservation in the Air Conditioning System
}

\author{
Fazri Amir ${ }^{1,3}$, Samsul Rizal ${ }^{2,}$, Rudi Kurniawan², Hamdani Umar ${ }^{2}$, Razali Thaib ${ }^{2}$ \\ ${ }^{1}$ Doctoral Program, School of Engineering, ${ }^{2}$ Department of Mechanical Engineering, ${ }^{3}$ Department of Mechanical Engineering \\ ${ }^{1,2}$ Universitas Syiah Kuala, ${ }^{3}$ Universitas Samudra \\ ${ }^{1,2}$ Banda Aceh, ${ }^{3}$ Langsa, Indonesia \\ *samsul.rizal@unsyiah.ac.id
}

\begin{abstract}
Population and economic growth affect the total energy demand and Air Conditioner (AC) electrical systems and economic growth. Energy conservation is needed to reduce the total energy used. Heat pipe heat exchangers (HPHE) are implemented to recover waste energy in air conditioning systems. This study has investigated the performance relationship between effectiveness and the Number of Transfer Units (NTU) in the system. One line of straight axis heat pipe is installed at the inlet and outlet. The configuration was shaky. Changes in temperature and humidity are measured to obtain energy conversion according to changes in air intake speed and temperature variations that enter the ducting. The application of HPHE in the air conditioning system can reduce energy consumption. The results showed that the relationship between effectiveness and NTU was linear. The effectiveness varies from 0.08 to 0.202 , and the relationship is expressed as $=1.14 N T U+0.0041$. Whereas for low temperature applications the effectiveness varies from 0.022 0.14 , the relationship is expressed as $=1765 \mathrm{NTU}+2.9$. These test results can be concluded that HPHE is economical for heat recovery systems in air conditioning systems.
\end{abstract}

Keywords-heat pipe heat exchanger, the air conditioning system, system

\section{INTRODUCTION}

Employment and economic growth affect the total energy demand; the electricity used by air conditioning systems increases along with economic growth. Demand for refrigeration systems is expected to grow tenfold by 2050 , the energy challenge of the 21 st century, namely increasing system efficiency [1]. From here, it is expected that energy consumption in the refrigeration system will increase. According to ASHRAE standards [2], rooms, especially in hospitals, have requirements for a Heating, Ventilating Air Conditioning (HVAC) system with a temperature range of 20 $40{ }^{\circ} \mathrm{C}$ and relative humidity of $30-60 \%$. HVAC systems are specially designed in always-on conditions and could supply air to a specific room. Therefore, the design in this room occupies the first position in energy consumption [3].
The idea of saving energy consumption by applying a heat pipe heat exchanger to the air conditioning system is maximum effectiveness of $38 \%$ at high inlet temperature and speed of 1.5 $\mathrm{m} / \mathrm{s}$, maximum energy recovery of 385 watts. According to Mohammad Rasouli et al. [4], energy-saving and indoor environmental quality (IEQ) are significant points of concern for designers, owners, researchers, and governments. It is challenging for all parties to participate in finding solutions to these problems.

Research on HPHE in the air conditioning system was also carried out by Mostafa A. Abd El-Baky et al. [5]. By utilizing the Heat Pipe Heat Exchanger in the AC system, fresh air is channeled into the ducting inlet (evaporator part) and returns to the air/exhaust air. Negin Monirimeh S et al. [6] experimented with a thermosiphon type used in heat pipe heat exchangers using methanol nanofluids. The value of HPHE effectiveness and energy savings in the reheating section increases and decreases in relative humidity and increases in temperature at the air inlet. Increasing the number of HPHE ducts will increase the energy-saving value of the pre-cool and reheat sections.

J. Danielewicz et al. [7], determining variables include Overall Heat Transfer, Effectiveness, Pressure Drop, and Heat Exchanger Task based on flow characteristics and thermosiphon configuration on the heat exchanger. The results with heat exchanger characteristics were studied by validating the $\varepsilon$-NTU heat transfer through the model to be tested. R410A as a working fluid is recommended because it can positively affect HPHE performance and its impact on the environment is better than R22 and R134a.

Xiao-Ping $\mathrm{Wu}$ et al. [8] conducted an experimental study using a thermosyphon heat pipe heat exchanger (HPHE) to regulate relative humidity, where the condenser from HPHE can be used as a heating device to replace conventional heating devices for controlling relative humidity where the required air supply is below $70 \% \mathrm{RH}$. The results showed that the system's cooling capability increased by about $20-32.7 \%$, and energy consumption became efficient. 
Abd El-Baky and Mohamed [5] experimentally tested the effectiveness of HPHE in the waste heat recovery process to reduce the cooling load by varying the ratio of mass flow rate and evaporator inlet temperature. It was found that the heat transfer effectiveness increased by $48 \%$ when the intake air temperature was $40^{\circ} \mathrm{C}$, and the increase in fresh air temperature led to an increase in heat recovery by up to $85 \%$.

Y.H. Yau and A.S. Tucker [9] used computer simulations to predict HPHE 6 axis free channel performance in tropical building HVAC systems under various operating conditions. The investigation results show that the heat transfer increases with the increasing slope angle of the HPHE and the relative humidity at the evaporator inlet. The efficiency is envisaging to amplified by providing a higher air velocity at the evaporator side. The experimental efficiency values fluctuated between 0.2 to 0.6 .

The previous research concluded that the Heat Pipe Heat Exchanger's crucial role is in saving energy. It was mainly concerning the hospital operating room air conditioning system/HVAC under a continuous operating condition so that research development would increase the whole system efficiency. The sustainability of HPHE is very much desirable. By making improvements to the design, in this case, the heat pipe configuration and the fin material, and the fluid used inside the heat pipe, it is expected that HPHE would increase the optimal efficiency and capability of heat recovery.

\section{Methodology}

\section{A. Design HPHE}

The heat exchanger pipe was designed to consist of tubular heat pipes arranged in several rows mounted on a galvanized iron frame. Each duct has been designed using multiple heat pipes in a staggered arrangement, as shown in Fig 1. At this design stage, the correct dimensions of the HPHE were obtained to be placed in the cooling duct.

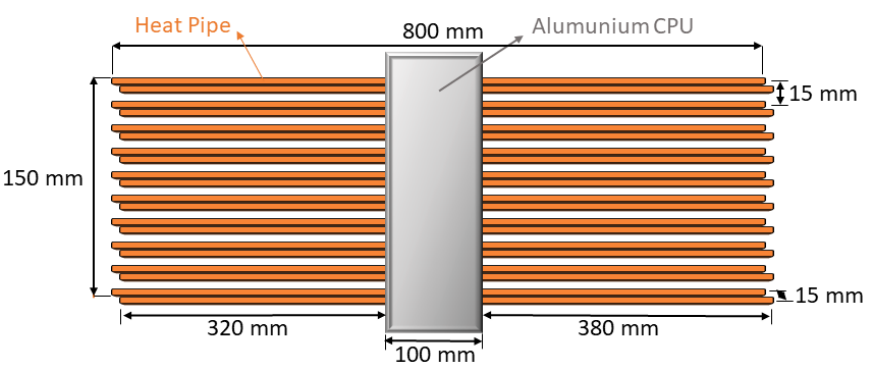

Fig. 1. Design heat pipe heat exchanger.

The entire heat transfer system was divided into three stages for simplicity of design; The heat enters the heat pipe from the hot air through the evaporator surface area by convection, then was transferred from the hot side to the cold side through the heat pipe through a process of conduction and a change in heat transfer phase and finally released to the cold side by convection through the surface area of the heat pipe condenser.
Heat capacity was the amount of heat that must be transferred per second for HPHE operations. The hot duty was calculated from the hot side and cold side air ducts. Critically, the two should be the same, but practically there was a large amount of heat lost due to conduction and convection to the environment. The heat duty stays on the safe side is calculated from the cold side air duct (Table 1).

TABLE I. HEAT CAPACITY

\begin{tabular}{cll}
\hline & \multicolumn{1}{c}{ Hot air } & \multicolumn{1}{c}{ Cold air } \\
\hline Inlet Temperature & $65{ }^{\circ} \mathrm{C}$ & $25{ }^{\circ} \mathrm{C}$ \\
\hline Outlet Temperature & $60{ }^{\circ} \mathrm{C}$ & $27{ }^{\circ} \mathrm{C}$ \\
\hline Velocitys & $1 \mathrm{~m} / \mathrm{s}$ & $2 \mathrm{~m} / \mathrm{s}$ \\
\hline Channel size & $0,2 \mathrm{~m} \times 0,2 \mathrm{~m}$ & $0,2 \mathrm{~m} \times 0,35 \mathrm{~m}$ \\
\hline
\end{tabular}

\section{B. Heat Capacity}

$$
\begin{aligned}
Q & =m \cdot c p \cdot D T=r \cdot \Delta v \cdot c p \cdot D T \\
& =1,17 \times 0,2 \times 0,35 \times 2 \times 1000 \times(27-25)=327,6 \mathrm{~W} .
\end{aligned}
$$

\section{Heat Exchanger Heat Pipe Manufacturing}

At this stage, it would be implemented in partner industries. The industry would prepare its facilities, among others, to manufacture that has been prepared for heat pipes. This industry has useful enough machine tools to support the manufacturing process and experience because the product from this partner is refrigeration equipment, both condenser and evaporator.

\section{HPHE Experimental Procedure}

Air Conditioning Systems equipped with Heat Pipe Heat Exchanger (HPHE) were tested at the Heat Transfer Laboratory of the Mechanical Engineering Study Program, Faculty of Engineering, Universitas Syiah Kuala. HPHE has arranged in a vertical position and a staggering shape. The HPHE has been designed as a vertical position between the ducting inlet air (intake air) and return air (air out). The position of the HPHE has placed before the cooling coil in the AC system, meaning that the incoming air has to get pre-cooling treatment from the HPHE, which reduced the total energy used. All experimental settings have shown in Figure 2.

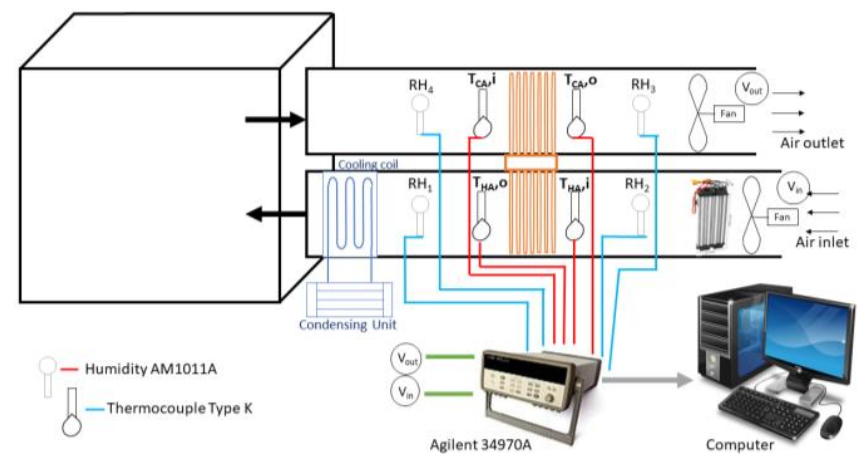

Fig. 2. Experimental setup. 


\section{RESULTS AND DISCUSSION}

The following equation can calculate the heat rate $(\mathrm{Q})$ for HPHE from the hot air side [10,11]:

$$
Q=m_{H A} \times C_{p, H A}\left(T_{H A, \text { in }}-T_{H A, \text { out }}\right)
$$

Where mHA is the mass of hot air flow rate, $C p, H A$ is the specific heat capacity of hot air, THA, in, and THA, out is the incoming and outgoing hot air temperature.

In the same way, the heart rate on the cold air side determined from:

$$
Q=m_{C A} \times C_{p, C A}\left(T_{C A, \text { in }}-T_{C A, \text { out }}\right)
$$

Where mHA was the mass of hot air flow rate $C p, \mathrm{CA}$ is the specific heat capacity of cold air, TCA, in, and TCA, has the intake air temperature, and the cold air temperature out.

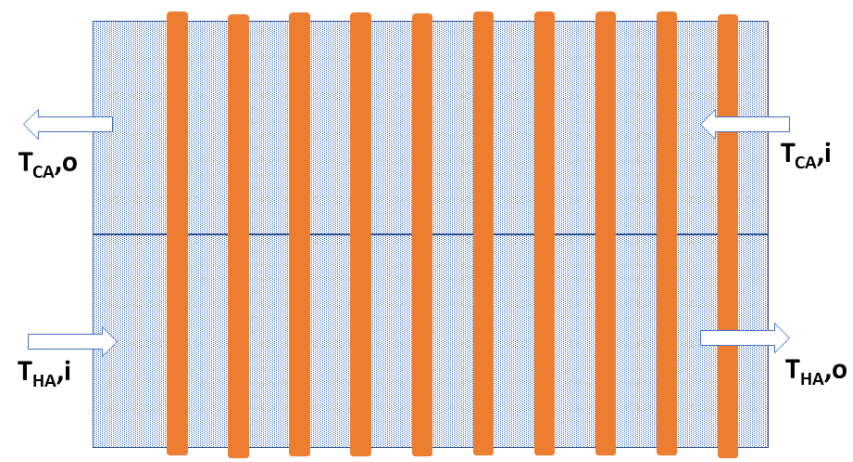

Fig. 3. Schematic of airflow in the HPHE system

The calculated cold side heat transfer rate has not the same as the hot side because there was significant heat loss. The cold side has been considered for calculating the heat transfer rate, thermal conductivity. The overall heat transfer coefficient, $U$ of HPHE has defined as follows, W/( $\left.\mathrm{m}^{2} \mathrm{~K}\right)[10,12-14]$

$$
U=\frac{Q}{A \times \Delta T_{l m}}
$$

Where $\mathrm{A}\left(\mathrm{m}^{2}\right)$ is the total heat transfer area of HPHE. $\triangle$ Tm $(\mathrm{K})$ is the logarithmic mean temperature difference, which is calculated for the counter-current arrangement as follows:

$$
\Delta T_{l m}=\frac{\left(T_{H A, \text { in }}-T_{C a, \text { out }}\right)-\left(T_{H A, \text { out }}-T_{C A, \text { in }}\right)}{\ln \left[\frac{\left(T_{H A, \text { in }}-T_{C a, \text { out }}\right)}{\left(T_{H A, \text { out }}-T_{C a, \text { in }}\right)}\right.}
$$

HPHE effectiveness has defined as the ratio of the actual heat transfer rate $(\dot{Q})$. The heat exchanger is given to the maximum possible heat transfer rate $(Q)$ :

$$
\varepsilon=\frac{\dot{Q}}{\dot{Q} \max }
$$

The maximum theoretical heart rate has calculated by the following equation:

$\dot{Q}_{\text {max }}=C_{\text {min }}\left(T_{H A, \text { in }}-T_{C A, \text { in }}\right)$

Where $\mathrm{Cmin}$ the minimum heating capacity of the hot air which has been taken from the hot capacity of hot air (CHA) and the hot capacity of cold air (CCA), kJ / K. where the following equation calculated $\mathrm{CHA}$ and $\mathrm{CCA}$

$$
\begin{aligned}
& C_{H A}=m_{H A} C_{p, H A} \\
& C_{C A}=m_{C A} C_{p, C A}
\end{aligned}
$$

The amount of the Number Thermal Unit (NTU) has a significant quantity of heat exchanger, which is determined from the relationship $[15,16]$ :

$$
N T U=\frac{U \times A}{C_{\min }}
$$

The total heat transfer coefficient is U. A is the surface area of the heat transfer. The $\varepsilon$-NTU method is a thermodynamic calculation for dividing the wall-type heat exchanger derived from the nondimensional equation, if the logarithmic mean temperature difference included in the consideration. The relationship of $\varepsilon$ and NTU is expressed by:

$$
\varepsilon=\frac{1-e^{[-1(1-R) N T U]}}{1-R \times e^{[-1(1-R) N T U]}}
$$

\section{A. HPHE Performance at Moderate Temperature}

Parameters such as heat transfer rate (W), overall heat transfer coefficient (U), effectiveness ( $\varepsilon$ ), and NTU were essential in the calculation of the HPHE performance. All these parameters were calculated regarding the experimental data to plot diagrams that are evaluating the performance. This test was performed in the case of a moderate temperature heat recovery system. In this system, the inlet air temperature has maintained between $60^{\circ} \mathrm{C}$ and $80^{\circ} \mathrm{C}$, and the cold air temperature has kept almost at atmospheric temperature.

\section{B. Heat Transfer Rate $(\dot{Q})$}

The heat transfer rate has calculated from the difference in the temperature of the hot air entering and leaving it and plotted by the variation in the mass flow rate of hot air. The mass flow rate of hot air was varied by keeping cold airflow at a constant value. Then the same test was repeated for different constant cold air mass flow rates.

This graph shows that the heat transfer rate increases with the increasing mass flow rate of hot air for a constant cold air mass flow rate. At high mass flow rates of hot and cold air, the heat transfer rate becomes maximum. In this test, the mass flow of cold air with a constant speed of $0.244 \mathrm{~kg} / \mathrm{s}$, a minimum heat 
transfer speed of $470.42 \mathrm{~W}$ at a mass flow rate of hot air of $0.04 \mathrm{~kg} / \mathrm{s}$, and a maximum of $1003.4 \mathrm{~W}$ at a mass of air hot flow rate of $0.124 \mathrm{~kg} / \mathrm{s}$. It was also found almost the same results for different tests at different constant cold air mass flow rates with varying hot air mass flow rates; The heat transfer rate varies from $476 \mathrm{~W}$ to $703 \mathrm{~W}$ for cold air mass flow rate of $0.197 \mathrm{~kg} / \mathrm{s}$ and varies from $430 \mathrm{~W}$ to $637 \mathrm{~W}$ for $0.152 \mathrm{~kg} / \mathrm{s}$. The increase in heat transfer rate with increasing mass flow rate is evident from this experiment's results. As the hot air flow rate increases, the heating power increases, and the thin layer of liquid changes to reach the boiling point of the core with a large number of bubbles, which increases the heat transfer rate and increases the heat exchange coefficient shown in Fig 4. Those show that efficiency Heat transfer can be increased by increasing the hot air flow rate in practice.

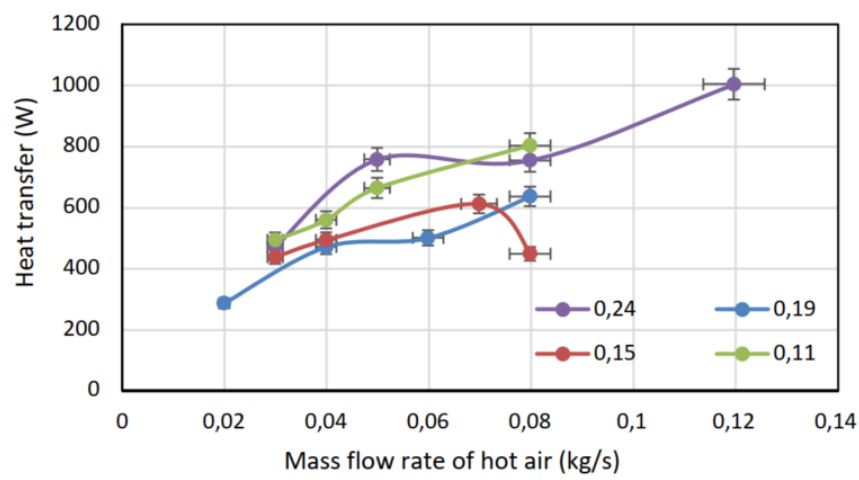

Fig. 4. Variation of heat transfer rate with the mass flow rate of air at moderate temperature differences.

\section{Overall Heat Transfer Coefficient $(U)$}

The most critical performance parameters of a heat exchanger are its overall heat transfer coefficient. This quantity is measured for each HPHE test using the heat transfer rate (W) of the difference in the cold air intake and exit temperature. Theoretically, the heat transfer rates on the hot and cold sides will be the same, but due to the conductive heat loss through the equipment setup and the convection heat loss to the air, some significant differences were observed in the tests. Using the cold side heat transfer rate is to stay on the safe side because it is lower than the hot side heat transfer rate. Using a smaller value for the heat transfer rate to calculate $U$ gives a more practical and valid result. The graph is plotted using the same procedure described earlier to plot the heat transfer rate curve.

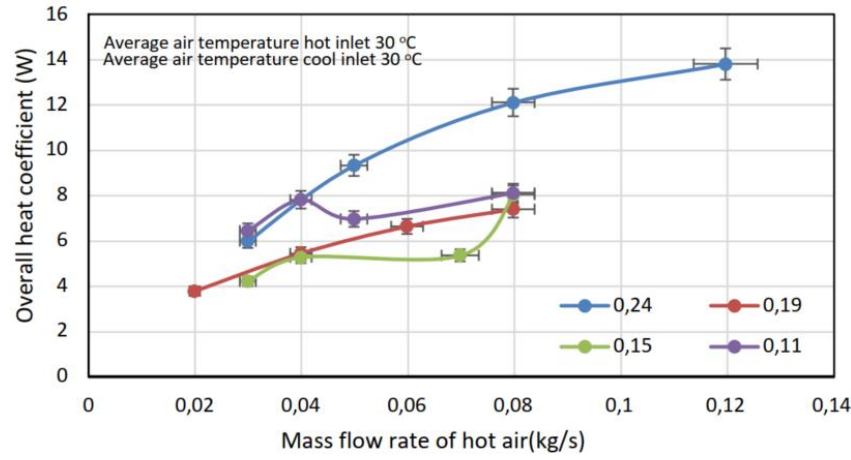

Fig. 5. Shows the variation of the overall heat transfer coefficient with changes in the mass flow rate of air at moderate temperature differences.

From this Fig. 5 it is known that the relationship between the overall heat transfer coefficient $(\mathrm{U})$ and the mass flow rate is the same as previously described. From the test results, it was found that the mass flow rate of cold air was constant at $0.2442 \mathrm{~kg} / \mathrm{s}$, the overall heat transfer coefficient increased from a minimum value of $6 \mathrm{~W} / \mathrm{m}-\mathrm{K}$ to a maximum value of 13.9 $\mathrm{W} / \mathrm{m}-\mathrm{K}$. When the mass flow rate of hot air is increased from $0.04 \mathrm{~kg} / \mathrm{s}$ to $0.124 \mathrm{~kg} / \mathrm{s}$, when compared with the mass flow rate of cold air, it can be concluded from the experimental data that the heat transfer coefficient also increases with the increase in the mass flow rate of cold air which varies from 4.2 to 7.8 $\mathrm{W} / \mathrm{mK}$ in cold air. the mass flow rate of $0.152 \mathrm{~kg} / \mathrm{s}$ and varies from $522 \mathrm{~W} / \mathrm{mK}$ to $10 \mathrm{~W} / \mathrm{mK}$ for cold air mass flow rate of $0.197 \mathrm{~kg} / \mathrm{s}$

\section{Effectiveness $(\boldsymbol{\varepsilon})$}

Effectiveness is also an important performance parameter for heat exchangers. This quantity is calculated from experimental data and plotted against the mass flow rate following the previous section's procedure.

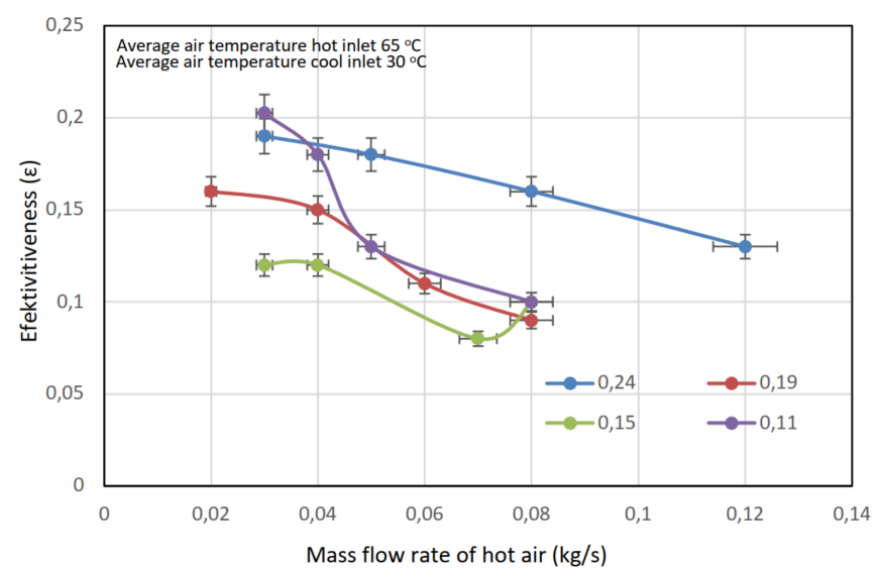

Fig. 6. The variation of HPHE effectiveness with air mass flow rates at moderate temperature differences.

This graph in Fig. 6 shows that the relationship between effectiveness and mass flow rate is different from the previous section. The effectiveness decreases with increasing the mass flow rate of hot air at a constant cold air mass flow rate. It is 
summarized from the test data analysis that for a cold air mass flow rate of $0.244 \mathrm{~kg} / \mathrm{s}$, the effectiveness decreases from 0.19 to 0.13 when the mass flow rate of hot air increases from 0.04 to $0.124 \mathrm{~kg} / \mathrm{s}$. HPHE was more effective for lower mass flow rates.

\section{E. Number of Transfer Units (NTU)}

A function of effectiveness is The Number of Transfer Units (NTU) and a critical performance parameter. The NTU has been calculated, and the graph on the plot shows the variation in effectiveness with NTU.

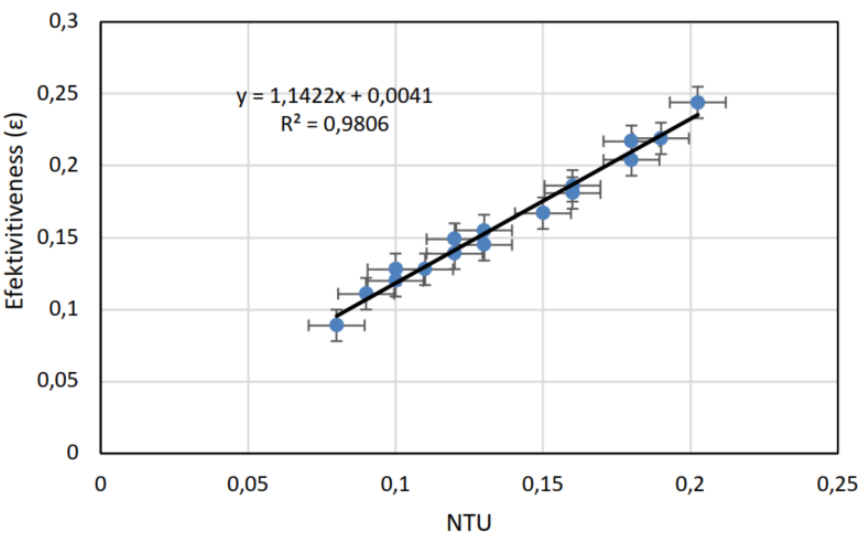

Fig. 7. Variations in the effectiveness of HPHE and NTU at moderate temperature differences

The graph in Fig. 7 portrays a linear relationship between efficiency and NTU, where NTU is proportionate to the heat transfer coefficient. As the heat transfer coefficient rises, the air mass flow rate also increases, which in turn NTU also upsurges, and affect the HPHE effectiveness. Effectiveness varies from 0.052 to 0.182 , and the relationship has expressed in a straight line where it fits best as $\varepsilon=1.14 \mathrm{NTU}+0.0041$.

\section{CONCLUSION}

In low-temperature heat recovery applications, the heat transfer rate increases along with increasing air mass flow rate. The effectiveness of HPHE decreased with the increasing mass flow rate and air velocity. The effectiveness and NTU demonstrate a linear relationship. The effectiveness varies from 0.08 to 0.202 , and the relationship has been expressed as $=$ $1.14 \mathrm{NTU}+0.0041$. For low-temperature applications, the effectiveness varies from $0.022-0.14$, the relationship is expressed as $=1765 \mathrm{NTU}+2.9$. The performance of the heat exchanger is susceptible to dust accumulation. The overall result concluded that HPHE is economical for heat recovery systems in air conditioning systems.

\section{REFERENCES}

[1] E.A. Goldstein, A.P. Raman, and S. Fan, "Sub-Ambient NonEvaporative Fluid Cooling with the Sky," Nat. Energy, vol. 2, 2017.
[2] U. Tun and H. Onn Malaysia, "Humidity Control In Different Building Applications; Restaurant And Operation Theatre Mohd Syafiq Syazwan Bin Mustafa Title Faculty of Mechanical and Manufacturing Engineering," 2017.

[3] ASHRAE, "ASHRAE Handbook: Systems and Equipment," Ashrae, 2000.

[4] M. Rasouli, G. Ge, C.J. Simonson, and R.W. Besant, "Uncertainties in Energy and Economic Performance of HVAC Systems and Energy Recovery Ventilators Due to Uncertainties in Building and HVAC Parameters," in Applied Thermal Engineering, 2013, vol. 50, no. 1, pp 732-742.

[5] M.A. Abd El-Baky and M.M. Mohamed, "Heat Pipe Heat Exchanger for Heat Recovery in Air Conditioning," Appl. Therm. Eng., vol. 27, no. 4 pp. 795-801, 2007.

[6] N. Monirimanesh, S.M. Nowee, S. Khayyami, and I. Abrishamchi, "Performance Enhancement of an Experimental Air Conditioning System by Using TiO2/Methanol Nanofluid in Heat Pipe Heat Exchangers," Heat Mass Transf. und Stoffuebertragung, vol. 52, no. 5, pp. 1025-1035, 2016.

[7] A.W. Politeknik, N. Bali, N. Putra, S. Muhammaddiyah, and A. Winarta "Experimental Study of Heat Pipe Heat Exchanger Multi Fin for Energy Efficiency Effort in Operating Room Air System Study on Boiling Hea Transfer in Narrow Channel Fro 3 Different Geometries View Project Metal Oxide Nanoparticles in Enhancing Thermal And ," Artic. Int. J. Technol., vol. 2, pp. 422-429, 2018.

[8] Xiao Ping Wu, P. Johnson, and A. Akbarzadeh, "Application of Heat Pipe Heat Exchangers to Humidity Control in Air-Conditioning Systems,” Appl. Therm. Eng., vol. 17, no. 6, pp. 561-568, 1997.

[9] Y.H. Yau and A.S. Tucker, "The Performance Study of a Wet Six-Row Heat-Pipe Heat Exchanger Operating in Tropical Buildings," Int. J. Energy Res., vol. 27, no. 3, pp. 187-202, 2003

[10] A.S. Kusumah, I.I. Hakim, R. Sukarno, F.F. Rachman, and N. Putra "The Application of U-Shape Heat Pipe Heat Exchanger to Reduce Relative Humidity for Energy Conservation in Heating, Ventilation, and Air Conditioning (HVAC) Systems," Int. J. Technol., vol. 10, no. 6, pp. $1202-1210,2019$.

[11] M.A.M. Hassan, "Investigation of Performance of Heat Pipe as Heat Exchanger Using Alternative Refrigerants," J. Energy Eng., vol. 139, no. 1, pp. 18-24, 2013.

[12] I.I. Hakim, N. Putra, A.P. Marda, M.A. Alvaro, and A. Winarta "Experimental Study on Utilization of Heat Pipe Heat Exchanger for Improving Efficiency of Clean Room Air System in Hospitals," E3S Web Conf., vol. 67, p. 02056, 2018.

[13] Y. Ismida, M. Amin, H. Umar, H. Amna, F. Amir, and C. Akbar, "Experimental Study of Heat-Absorbent Foam Concrete Wall Based Macro-Encapsulation of Beef Tallow/Damar Gum in Building," in IOP Conference Series: Materials Science and Engineering, 2019, p. 536.

[14] S. Hossen, A.M. Morshed, A. Tikadar, A.S. Salman, and T.C. Paul, "EXPERIMENTAL INVESTIGATION OF HEAT PIPE HEAT EXCHANGER (HPHE) FOR WASTE HEAT RECOVERY APPLICATION," in 4th Thermal and Fluids Engineering Conference, Jul. 2019, pp. 843-851.

[15] H. Tanujaya and I.W. Sukania, "Experimental Study of StationaryHead/Channel Cover STHE Prototype Using $\varepsilon$-NTU Method,” Exp. Tech., vol. 43, no. 6, pp. 645-655, 2019.

[16] T.U.H.S.G. Manik, T.B. Sitorus, M.L. Panjaitan, and Y.O. Saragih, "The Experimental and Simulation Study of an Earth-Air Heat Exchanger in Medan City," in IOP Conference Series: Materials Science and Engineering, Jul. 2019, vol. 505, no. 1, p. 012104. 